\title{
Anteseden dari Green Buying Behaviour
}

\author{
Dika Septariana, Luki Adiati Pratomo \\ Fakultas Ekonomi dan Bisnis, Universitas Trisakti \\ e-mail: Luki.adiati@trisakti.ac.id
}

\begin{abstract}
The aim of this study is to examine the factors that can influence green buying behavior. Factors to be investigated are personal norm, social environmental norm, peer influence, and green self-identity. The research design used in this study is hypothesis testing with a purposive sampling technique. The number of respondents is 200, with the specific criteria is consumers who understand and consume environmentally friendly products in the past year. The results showed that the four variables, namely personal norm, social environmental norm, peer influence, green self-identity, had a positive influence on green buying behavior.
\end{abstract}

Keywords: personal norm, social environmental norm, peer influence, green self-identity, green buying behaviour

\begin{abstract}
Abstrak
Tujuan dari penelitian adalah menguji faktor-faktor yang dapat mempengaruhi green buying behaviour. Faktor-faktor yang akan diteliti adalah personal norm, social environmental norm, peer influence, dan green self-identity. Rancangan penelitian yang digunakan adalah pengujian hipotesis dengan teknik purposive sampling. Jumlah responden adalah 200 orang dengan kriteria konsumen yang memahami dan mengkonsumsi produk ramah lingkungan dalam setahun terakhir. Hasil penelitian menunjukkan bahwa keempat variabel yaitu norma personal, norma lingkungan sosial, pengaruh teman sebaya, identitas diri pada produk hijau, mempunyai pengaruh yang positif terhadap green buying behaviour.
\end{abstract}

Kata kunci: norma personal, norma lingkungan sosial, pengaruh teman sebaya, identitas diri pada produk hijau, perilaku pembelian produk hijau 


\section{PENDAHULUAN}

Kesadaran untuk menjaga lingkungan alam sudah mulai berkembang di masyarakat, sehingga membentuk perilaku tertentu yang berkaitan dengan produk ramah lingkungan (Moser, 2015). Semakin tinggi kesadaran konsumen akan pentingnya menjaga lingkungan, maka sangat mungkin konsumen berkeinginan untuk membeli produk yang ramah lingkungan atau sering disebut produk hijau (Anvar \& Venter, 2014; Jansson, Marell, \& Nordlund, 2010). Walaupun masih banyak diperdebatkan, apakah konsumen yang sadar akan lingkungan pada akhirnya akan membeli produk ramah lingkungan (Sukhu \& Scharff, 2010), sehingga banyak penelitian dilakukan untuk lebih memahami faktor apa saja yang mendorong konsumen untuk benar-benar membeli produk hijau tersebut (Anvar \& Venter, 2014; Kim \& Choi, 2005; Moser, 2015). Perilaku konsumen dalam membeli produk ramah lingkungan menjadi topik yang sangat penting, baik bagi peneliti maupun praktisi, mengingat bahwa kesadaran saja masih belum cukup membuat konsumen melakukan pembelian produk hijau (Sukhu \& Scharff, 2010). Masih diperlukan faktor-faktor lain agar konsumen sampai pada keputusan pembelian.

Berdasarkan kerangka kerja dari theory of planned behavior (TPB), perilaku konsumen merupakan tujuan akhir perusahaan yang dibentuk oleh intensi konsumen untuk melakukan tindakan pembelian (Ajzen, 1991). Sementara itu, untuk menumbuhkan intensi atau keinginan untuk membeli, perlu beberapa faktor yang mendorongnya, seperti attitude, subjective norm dan perceived behavioral control (Ajzen, 1991). Selain itu, (Klöckner \& Ohms, 2009) juga mengungkapkan bahwa terdapat dua faktor lain yaitu personal norms dan social norms yang memiliki pengaruh terhadap behaviour
Dalam rangka memahami perilaku pembelian produk ramah lingkungan, TPB merupakan salah satu sumber yang sangat membantu. Setyawan dkk. (2018) menguraikan bahwa subjective norm, perceived behavioral control dan willingness to pay merupakan faktor-faktor yang mendorong konsumen membeli produk yang ramah lingkungan. Moser (2015) menyatakan bahwa personal norms dan social norm memiliki pengaruh terhadap green purchasing behaviour. Lee (2009) dalam penelitiannya membuktikan bahwa peer influence dan self-identity berpengaruh terhadap green purchasing behaviour. Sementara itu, Khare (2015) dalam penelitiannya menyatakan bahwa personal norms, social environmental norm, peer influence dan green self identity merupakan beberapa faktor yang dapat mengubah perilaku konsumen menjadi perilaku membeli produk hijau atau green buying behaviour.

Perilaku pembelian produk hijau juga menjadi isu penting di Indonesia, mengingat bahwa pemanfaatan alam yang berlebihan telah menjadi salah satu masalah di Indonesia. Sangat penting membangun kesadaran konsumen Indonesia untuk ikut memelihara alam Indonesia dengan cara membeli produk dan jasa yang ramah lingkungan. Setyawan dkk. (2018) ketika meneliti konsumen muda Indonesia menemukan bahwa walaupun konsumen mempunyai sikap positif terhadap produk ramah lingkungan, ternyata tidak berhasil mendorong mereka untuk betulbetul melakukan pembelian produknya. Walaupun konsumen Indonesia berpendapat bahwa masalah lingkungan yang dihadapi saat ini disebabkan oleh perilaku mereka (environmental locus of control), tetapi pada saat mereka harus melakukan pembelian dengan harga yang lebih mahal, ternyata konsumen tidak bersedia membeli produk hijau tersebut (Pratiwi \& Pratomo, 2018). 
Hasil-hasil penelitian tersebut menunjukkan bahwa masih ada perbedaan pendapat mengenai faktor-faktor apa saja yang sebenarnya mendorong konsumen untuk membeli produk hijau, khususnya di Indonesia. Penelitian ini perlu dilakukan untuk menutup kesenjangan yang terjadi dengan menginvestigasi lebih jauh peranan beberapa faktor yaitu personal norms, social environmental norm, peer influence dan green self indentity terhadap green buying behaviour pada produk yang ramah lingkungan.

Personal norms adalah norma-norma yang ada pada diri manusia yang secara langsung mengatur segala tindakan yang akan dilakukan, konsekuensi yang akan diterima jika seseorang melakukan tindakan yang salah yaitu berupa sanksi atau imbalan (perasaan bersalah atau kesenangan) dan terlepas dari pendapat orang lain (Kinzig dkk., 2013). Karakterisik utama dari personal norms adalah adanya keinginan pada diri individu untuk mengikutinya dan tidak didasarkan pada rasa takut atau sanksi sosial melainkan mucul rasa penyesalan atau bersalah (Bamberg dkk., 2007).

Personal norms atau norma pribadi muncul dari kesadaran bahwa individu harus bertindak dengan benar dalam situasi tertentu agar tidak merugikan orang lain (Klöckner \& Ohms, 2009). Norma pribadi akan menimbulkan penyesalan atau rasa bersalah pada diri individu setelah mereka melakukan tindakan yang salah (Bamberg dkk., 2007), sehingga personal norms dapat menjadi prediktor yang penting dari perilaku pelestarian lingkungan (Klöckner \& Ohms, 2009). Bahkan norma pribadi tersebut akan mendorong konsumen bersedia membeli produk organik yang ramah lingkungan (Klöckner \& Ohms, 2009).

Social environmental norm merupakan aturan yang membatasi perilaku individu dalam bertindak di lingkungan masyarakat
(Ellickson, 2001). Mereka yang melanggar norma sosial tersebut akan diberikan sanksi sosial dan bagi mereka yang menaati aturan tersebut akan diberikan imbalan (Ellickson, 2001). Orang-orang yang melanggar social norm akan mendapatkan hukuman berupa gosip negatif dan dikucilkan dari pergaulan/masyarakat (Ellickson, 2001). Social norm dapat menjadi sebuah tekanan sosial yang dirasakan individu dalam berperilaku (Aertsens dkk., 2009). Social norm berhubungan dengan bagaimana orang lain mengharapkan individu untuk bertindak dan bagaimana mengharapkan orang lain bertindak untuk individu (Follows \& Jobber, 2000). Sedangkan menurut (Maxwell \& Garbarino, 2010), social norm dapat berupa preskriptif (apa yang orang harus lakukan) atau proskriptive (apa yang tidak boleh orang lakukan).

Social norm dapat mengatur perilaku individu dalam berinteraksi dengan orang lain (Young, 2007). Sosial norm adalah aturan yang ada pada masyarakat yang secara langsung membatasi dan mempengaruhi perilaku seseorang. Pengaruh tersebut dapat dirasakan sebagai tekanan sosial atau sebagai harapan dari individu kepada individu lain dan individu pada kelompoknya (Olsen \& Grunert, 2010). Bamberg dkk. (2007) dalam penelitiannya mengatakan bahwa social norm mempunyai pengaruh langsung pada behaviour meskipun pengaruh social norm tersebut lemah.

Pengertian dari peer influence itu sendiri adalah kelompok dengan usia yang relatif sama yang saling berinteraksi secara teratur (Ryan, 2001). Peer influence merujuk kepada tekanan dari sekelompok orang dari kelompok usia yang sama, mempunyai minat yang sama dan memiliki kategori sosialbudaya yang sama dan dapat membuat seseorang mengubah perilaku sikap dan nilai-nilai mereka sesuai dengan normanorma kelompok agar tidak dikucilkan oleh kelompoknya (Gupta \& Gupta, 2015). 
Konsumen berkomunikasi dengan rekanrekan mereka, mengamati perilaku mereka, menerima pendapat dari mereka, mencari informasi untuk membangun sikap dan selfconcept mereka sendiri (Gupta \& Gupta, 2015).

Kuatnya pengaruh peer influence bahkan dapat mempengaruhi keputusan konsumen dalam melakukan pembelian produk (Opoku, 2012). Khususnya pada kelompok dewasa muda, pengaruh peer influence cukup kuat dalam mendorong konsumen untuk membeli produk mewah yang dapat dilihat oleh teman-temannya (Makgosa \& Mohube, 2007). Bahkan pemilihan dan pembelian makanan kecil pada konsumen remaja, terlihat kuatnya peranan peer influence dalam pengambilan keputusannya (Norgaard dkk., 2013). Khusus produk ramah lingkungan memang belum banyak yang melakukan penelitian khusus tentang pentingnya peranan peer influence terhadap keputusan pembeliannya, tetapi secara umum beberapa peneliti menemukan bahwa lingkungan sosial, dalam hal ini keluarga dan teman memang dapat mempengaruhi konsumen membeli produk hijau (Cheah \& Phau, 2011; Lee, 2009).

Persepsi dan evaluasi tentang diri konsumen (self-identity) dapat berpengaruh pada pola konsumsi mereka karena persepsi dan evaluasi tersebut dapat membantu mereka dalam membedakan diri dengan orang lain (Khare, 2015). Self-indentity konsumen dapat terbentuk dari tradisi dan nilai-nilai yang berasal dari keluarga yang telah dipandang sebagai ungkapan dan perwujudan bagi konsumen dalam membangun dan mempertahankan diri mereka (WoodruffeBurton \& Wakenshaw, 2011) Perilaku konsumen yang peduli terhadap lingkungan dapat digunakan untuk pembentukan selfidentity (Hopper \& Nielsen, 1991). Selfidentity dapat dibangun dan dipelihara melalui pengalaman, ekspresi diri dengan nilai-nilai dan keyakinan yang mereka miliki dan dapat juga melalui produk yang dipilih (Woodruffe-Burton \& Wakenshaw, 2011). Ethical self-identity juga merupakan faktor penting dalam mendorong konsumen untuk membeli produk organik yang sehat bagi konsumen dan sekaligus aman bagi lingkungan (Michaelidou \& Hassan, 2008). Selanjutnya hasil penelitian Khare (2015) menyatakan bahwa self-identity dan selfconcept dapat mempengaruhi konsumen untuk melakukan green purchase.

Studi mengenai hubungan antara orientasi perilaku yang sadar akan lingkungan dan green buying behaviour bisa membantu untuk memahami lebih dalam lagi bagaimana perilaku seorang konsumen terhadap pembelian produk ramah lingkungan (Akehurst dkk., 2012). Konsumen menyadari dampak dari perilaku mereka terhadap lingkungan dan semakin banyak konsumen yang membeli green product bahkan setuju untuk membayar lebih untuk green product (Anvar \& Venter, 2014). Jika konsumen telah menemukan manfaat dari green product dan kemudian menyebabkan terjadinya pembelian serta konsumsi, dapat disimpulkan bahwa perilaku konsumen tersebut dapat mengacu kepada green buying behaviour (Anvar \& Venter, 2014).

Klöckner \& Ohms (2009) berpendapat bahwa personal norms mempunyai pengaruh terhadap behaviour individu meskipun pengaruh tersebut tidak secara langsung. Klöckner \& Ohms (2009) dalam penelitiannya menunjukkan personal norms mempunyai pengaruh yang cukup kuat dalam mendorong individu untuk berperilaku ramah lingkungan. Begitu juga salah satu studi tentang green buying behaviour menunjukkan bahwa nilainilai dan gaya hidup adalah hal yang penting dalam menjelaskan prioritas konsumen untuk green buying behaviour (Khare, 2015). Berdasarkan berbagai teori tersebut, maka penelitian ini membangun hipotesa sebagai berikut: 
H1 : Personal Norm mempunyai pengaruh positif terhadap Green Buying Behaviour

Social norm didefinisikan sebagai norma yang mengatur nilai-nilaidan sikap individu dalam hidup bermasyarakat (Ahn dkk., 2012). Social norm bertujuan untuk mengukur pengaruh lingkungan sosial terhadap perilaku individu (Olsen \& Grunert, 2010). Orang mengharapkan orang lain untuk bertindak dalam cara yang tepat secara moral, dan pada gilirannya mereka mengharapkan hal yang sama dengan orang lain (Ahn dkk., 2012). Studi lain menemukan bahwa social norm mempunyai pengaruh terhadap behaviour individu (Klöckner \& Ohms, 2009). Begitu juga penelitian dari Reynolds dkk., (2015) tentang social norms menjelaskan bahwa social norm memiliki pengaruh terhadap behaviour. Berdasarkan berbagai hasil penelitian terdahulu tersebut, maka penelitian ini menghasilkan hipotesa sebagai berikut:

H2: Social Environmental Norm mempunyai pengaruh positif terhadap Green Buying Behaviour

Peer influence mengacu kepada pengaruh yang meliputi sekelompok orang dari usia yang sama, minat yang sama dan memiliki kategori sosial-budaya yang sama untuk mengubah perilaku anggota kelompoknya dan biasanya sikap dan nilainilai yang diberikan harus sesuai dengan norma-norma yang ada dalam kelompok (Gupta \& Gupta, 2015). Makgosa \& Mohube (2007) menjelaskan bahwa peer influence mempunyai keterlibatan dalam pemilihan produk yang cukup tinggi, keterlibatan tersebut berkaitan dengan perspektif individu tentang sebuah merek. Newnham (2007) berpendapat bahwa peer influence mempunyai pengaruh terhadap perilaku mahasiswa perhotelan. Sementara penelitian dari Norgaard dkk. (2013) dalam penelitiannya menemukan bahwa peer influence dapat mempengaruhi perilaku remaja dalam pemilihan makanan kecil mereka. Kesesuaian individu dalam kelompok dan social noms dianggap sangat penting bagi konsumen dalam hidup bermasyarakat karena dapat mempengaruhi perilaku pembelian yang ramah lingkungan (Khare, 2015). Berdasarkan berbagai hasil penelitian sebelumnya, maka penelitian ini menghasilkan hipotesa sebagai berikut:

H3: Peer Influence mempunyai pengaruh positif terhadap Green Buying Behaviour

Konsumen di negara maju sangat menyadari dampak yang diterima lingkungan dari hasil limbah produksi industri dan juga dampak dari perilaku konsumsi sekarang yang sedang terjadi (Niinimäki, 2010). Kesadaran konsumen timbul melalui informasi-informasi tentang product lifecycle dan berbagai masalah yang terjadi pada lingkungan jika perilaku tersebut tidak diubah dengan demikian konsumen akan lebih bijaksana dalam memilih produk yang lebih ramah lingkungan (Niinimäki, 2010). Khare (2015) dalam penelitiannya menyatakan bahwa konsumen yang membeli green product bisa memberikan status bahwa konsumen tersebut pro-lingkungan, memungkinkan mereka untuk berkomitmen terhadap lingkungan, dan membedakan diri dari konsumen lain (self-identity). Berdasarkan argumentasi tersebut, maka penelitian ini menghasilkan hipotesa sebagai berikut:

H4 : Green Self-identity Norm mempunyai pengaruh positif terhadap Green Buying Behaviour. 


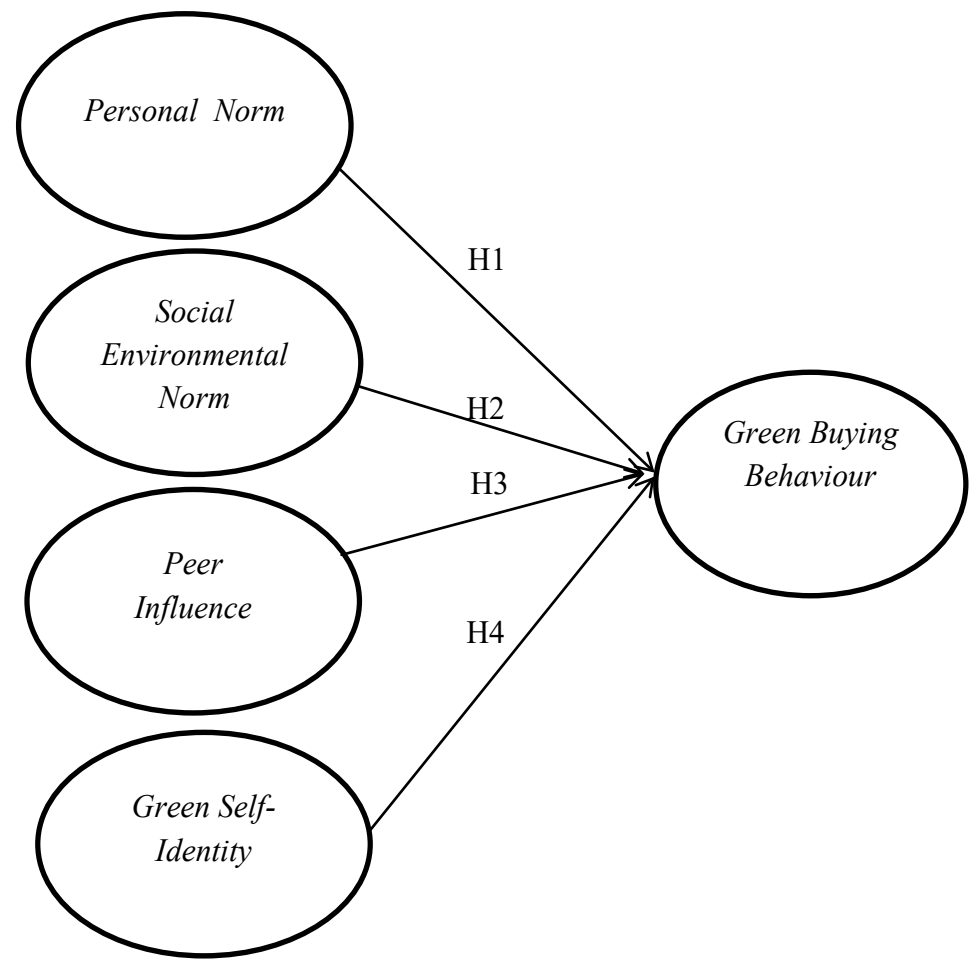

Gambar 1. Rerangka Pemikiran

\section{METODE PENELITIAN}

Sesuai dengan hipotesa yang dibentuk, penelitian ini akan menggunakan alat ukur untuk lima variabel berdasarkan beberapa penelitian sebelumnya. Variabel personal norm yang terdiri dari empat indikator merupakan adaptasi dari (Ahn dkk., 2012), kemudian lima indikator dari variabel social environmental norm merupakan pengembangan dari Ahn dkk., (2012), sedangkan variabel peer influence yang terdiri dari lima indikator dikembangkan dari penelitian (Lee, 2009). Dua variabel yang lain yaitu green self-identity dan green buying behaviour yang masing-masingnya menggunakan tiga dan enam indikator yang merupakan adaptasi dari studi yang dilakukan oleh Khare (2015).

Data dikumpulkan menggunakan kuesioner secara daring kepada 237 responden, tetapi setelah dilakukan pemeriksaan, hanya 200 kuesioner yang dapat digunakan. Metode penarikan sampel yang digunakan adalah non probability sampling dengan tehnik purposive sampling yang membutuhkan kriteria tertentu sesuai dengan kebutuhan penelitian. Berdasarkan tujuan penelitian, maka ditentukan bahwa kriteria sampel adalah konsumen yang memahami dan kemudian juga mengkonsumsi produk yang ramah lingkungan, minimum satu tahun terakhir.

Penelitian ini melakukan pengujian validitas dan reliabilitas atas instrumen yang digunakan. Berdasarkan hasil pengujian menunjukkan bahwa semua indikator adalah valid karena nilai factor loading-nya melebihi 0,40, sesuai dengan penjelasan dari Hair dkk. (2010). Selanjutnya uji reliabilitas yang menggunakan dasar dari Cronbach's Alpha, ditemukan nilai semua variabel berada antara 0,70 dan 0,90 , yang berarti instrumen yang digunakan reliabel.

\section{HASIL DAN PEMBAHASAN}

Penelitian ini menggunakan Structural Equation Modelling (SEM) untuk menguji hipotesis. 
Tabel 1. Hasil Uji Hipotesis

\begin{tabular}{clllc}
\hline \multicolumn{1}{c}{ Hipotesa } & Koefisien & P-value & Keputusan \\
\hline $\mathrm{H}_{1}:$ & $\begin{array}{l}\text { Personal Norms berpengaruh positif } \\
\text { terhadap Green Buying Behaviour. }\end{array}$ & 0,368 & 0,004 & Ha1: didukung \\
$\mathrm{H}_{2}: \begin{array}{l}\text { Social Environmental Norm berpengaruh } \\
\text { positif terhadap Green Buying Behaviour. }\end{array}$ & 0,068 & 0,028 & Ha2: didukung \\
$\mathrm{H}_{3}: \begin{array}{l}\text { Peer Influence berpengaruh positif } \\
\text { terhadap Green Buying Behaviour. }\end{array}$ & 0,441 & 0,000 & Ha3: didukung \\
$\mathrm{H}_{4}: \begin{array}{l}\text { Green Self-identity mempunyai pengaruh } \\
\text { positif terhadap Green Buying Behaviour. }\end{array}$ & 0,024 & 0,005 & Ha4: didukung \\
\hline
\end{tabular}

Berdasarkan Tabel 1 diketahui bahwa terdapat pengaruh positif personal norm terhadap green buying behaviour. Konsumen yang memiliki personal norm yang kuat dapat meningkatkan kemungkinan terjadinya perubahan pola konsumsi dari waktu ke waktu untuk perilaku konsumen yang lebih ramah lingkungan. Jika konsumen memiliki personal norm yang kuat untuk peduli dan bertanggung jawab terhadap lingkungan dan akan melakukan berbagai cara agar tidak merusak lingkungan maka secara langsung konsumen akan menjadikan produk-produk yang ramah lingkungan sebagai pilihan pertama untuk memenuhi kebutuhan mereka. Hasil penelitian ini mendukung beberapa studi sebelumnya, seperti yang dilakukan oleh Klöckner \& Ohms (2009) yang menemukan bahwa perilaku pembelian susu yang aman secara ekologis dipengaruhi oleh personal norms konsumen. Begitu juga hasil studi dari (Moser, 2015) mengenai belanja konsumsi sehari-hari masyarakat Jerman yang mengonfirmasi bahwa konsumen yang mempunyai norma pribadi berorientasi lingkungan akan bersedia membeli produk hijau walaupun harganya lebih mahal. Cukup menarik terjadi pada konsumen India (yang merupakan negara sedang berkembang) juga sudah mulai bersedia membeli produk ramah lingkungan ketika konsumen mempunyai norma pribadi yang sadar akan lingkungan (Khare, 2015).
Selanjutnya, berdasarkan Tabel 1 diketahui bahwa social environmental norm mempunyai pengaruh positif terhadap green buying behaviour. Social environmental norm dapat memaksa individu untuk bertindak sesuai aturan yang berlaku di lingkungan mereka, di dalam norma sosial terdapat hukuman yang berlaku yaitu berupa gosip negatif dan dikucilkan dari masyarakat. Social norm juga dapat menjadi sebuah tekanan sosial yang dirasakan individu dalam berperilaku di lingkungannya. Jika dalam lingkungan tempat tinggal individu memiliki social norm yang kuat untuk selalu menjaga lingkungan, maka secara langsung memaksa individu untuk mematuhi pertauran dan ikut berpartisipasi dalam menjaga dan melestarikan lingkungan dan juga dengan memiliki social environmental norm yang kuat untuk peduli terhadap lingkungan akan dapat membantu mengatasi masalah lingkungan di dunia. Hasil penelitian ini sejalan dengan hasil-hasil studi sebelumnya, misalnya bagaimana peranan social norm pada masyarakat Norwegia pada akhirnya mendorong konsumen untuk makan ikan yang merupakan makanan sehat bagi konsumen (Olsen \& Grunert, 2010). Sangat menarik bahwa hasil studi ini sesuai dengan uraian dari (Reynolds dkk., 2015), bahwa perubahan perilaku sangat dipengaruhi oleh social norm, apakah sesuai dengan pendapat orang lain, khususnya yang berpengaruh besar terhadap mereka. 
Menarik untuk diketahui bahwa walaupun belum banyak penelitian mengenai peranan peer influence terhadap green buying behaviour, ternyata studi ini menegaskan bahwa semakin kuat pengaruh teman sebaya mengenai pentingnya menjaga lingkungan, maka semakin besar pula kemungkinan konsumen membeli produk hijau. Peer influence akan sangat kuat pengaruhnya jika konsumen percaya bahwa saran yang diberikan oleh rekan merupakan saran terbaik. Terutama pada saat individu dihadapkan pada pilihan yang menyangkut merek dan produk yang akan dibelinya. Jika banyak dari teman mereka yang mengkonsumsi produk ramah lingkungan dan mulai merasakan manfaat dan keuntungan yang akan didapat, maka secara langsung akan mempengaruhi perilaku mereka untuk membeli produk yang ramah lingkungan. Hasil penelitian ini memperkuat berbagai penelitian mengenai peranan peer influence terhadap perilaku individu, walaupun bukan spesifik produk ramah lingkungan (Makgosa \& Mohube, 2007). Begitu juga penelitian mengenai makanan kecil, peranan teman sebaya sangat kuat dalam pemilihannya, sebagaimana yang diteliti oleh (Nørgaard dkk., 2013). Khusus untuk produk ramah lingkungan, ternyata hasil studi ini mendukung penelitian yang dilakukan Khare (2015) di India, peranan teman sebaya sangat kuat mendorong konsumen untuk membeli produk hijau.

Lalu berdasarkan Tabel 1 diketahui bahwa terdapat pengaruh positif green selfidentity terhadap green buying behaviour. Konsumen yang memiliki green self-identity akan beranggapan bahwa produk ramah lingkungan merupakan produk yang paling baik dan dengan mengkonsumsi green product dapat memberikan status konsumen yang pro-lingkungan dan sebagai pembeda diri mereka dengan orang lain. Konsumen yang merasa bangga menjadi pribadi yang berwawasan lingkungan akan menyebabkan mereka lebih suka membeli produk yang bisa didaur ulang, bahkan bersedia membawa tas sendiri ketika berbelanja. Kesadaran konsumen timbul melalui berbagai informasi tentang masalah yang terjadi pada lingkungan jika perilaku tersebut tidak diubah. Dengan demikian, konsumen akan lebih bijaksana dalam memilih produk yang lebih ramah lingkungan (Niinimäki, 2010). Salah satu penelitian di Hongkong juga membuktikan bahwa ketika konsumen mengidentifikasi dirinya sebagai orang yang berwawasan lingkungan, maka mereka akan membeli produk yang ramah lingkungan (Lee, 2009). Hasil studi ini juga sesuai dengan penelitian mengenai bahan pakaian organik di Amerika yang menemukan bahwa konsumen yang membeli produk organik adalah mereka yang mengidentifikasi dirinya sebagai pribadi yang memperhatikan lingkungan alam (Hustvedt \& Dickson, 2009).

\section{SIMPULAN DAN SARAN}

Berdasarkan hasil penelitian, dapat ditarik kesimpulan bahwa personal norm, social environmental norm, peer influence, green self-identity berpengaruh positif dan signifikan terhadap green buying behaviour. Terdapat beberapa masukan yang dapat disampaikan pada perusahaan. Pertama, membuat kampanye menarik yang bersifat persuasif berupa iklan di televisi, koran, surat kabar, radio dan beberapa media sosial yang berisikan tentang ajakan kepada para konsumen untuk lebih peduli terhadap lingkungan dan konsumen memiliki kewajiban untuk menggunakan energi dengan benar dan bijak. Kedua, perusahaan harus membuat konsumen memahami dan mematuhi social enviromental norm agar mereka lebih peduli terhadap lingkungan dengan membeli produk ramah lingkungan. Beberapa cara yang dapat dilakukan yaitu perusahaan dan manajer pemasaran di dalam promosinya berusaha untuk memberikan informasi dan pengetahuan tentang udara yang tercemar akibat polusi udara yang 
disebabkan oleh asap pabrik, asap kendaraan, asap yang disebabkan oleh pembakaran sampah daun dan asap-asap rokok agar banyak orang yang tidak mendiskusikan dan meributkan tentang polusi udara namun lebih peduli, mengatasi dan cepat tanggap akan bahaya polusi udara.

Ketiga, perusahaan harus mendorong konsumen lebih percaya pada teman agar mereka ingin membeli produk ramah lingkungan. Beberapa cara yang dilakukan yaitu perusahaan dan manajer pemasaran berusaha untuk melakukan promosi berupa diskon yang lebih besar dalam pembelian produk kepada konsumen jika mereka berhasil mengajak teman mereka untuk menggunakan produk ramah lingkungan yang tersedia pada toko tersebut. Keempat, perusahaan harus mendorong konsumen agar memiliki green self-identity agar mereka ingin membeli produk ramah lingkungan. Beberapa cara yang dilakukan yaitu perusahaan dan manajer pemasaran lebih gencar untuk melakukan promosi menarik yang bersifat persuasif berupa iklan di televisi, koran, surat kabar, radio dan beberapa media sosial yang berisikan tentang ajakan kepada para konsumen untuk mendukung segala tindakan perlindungan lingkungan dan membuat mereka merasa adalah orang yang bertanggung jawab penuh terhadap lingkungan.

\section{Keterbatasan Penelitian}

Walaupun penelitian ini sudah dirancang sebaik-baiknya, tetap ada beberapa keterbatasan yaitu produk ramah lingkungan yang diteliti hanya lampu hemat energi, baterai alkaline bebas merkuri, sayuran organik, beras organik, kantong plastik ramah lingkungan. Disarankan penelitian selanjutnya dapat mengembangkan lebih banyak produk ramah lingkungan lainnya. Keterbatasan lain adalah variabel yang diteliti terdiri dari personal norms, social environmental norm, peer influence, green self-identity dan green buying behaviour. Penelitian selanjutnya dapat mengeksplorasi lebih banyak variabel yang mungkin dapat mempengaruhi perilaku pembelian seperti willingness to pay more (Moser, 2015).

\section{REFERENSI}

Aertsens, J., Verbeke, W., Mondelaers, K., \& van Huylenbroeck, G. (2009). Personal determinants of organic food consumption: a review. British Food Journal, Vol. 111, No.10, 1140-1167. https://doi. org/10.1108/00070700910992961.

Ahn, J. M., Koo, D. M., \& Chang, H. S. (2012). Different impacts of normative influences on proenvironmental purchasing behavior explained by differences in individual characteristics. Journal of Global Scholars of Marketing Science, Vol. 22, Issue 2, 163-182. https://doi.org/ 10.1080/12297119.2012.655098.

Ajzen, I. (1991). The Theory of Planned Behavior. Organizational Behavior and Human Decision Procesess, Vol. 50, No. 2, 179211. https://doi.org/10.1922/ CDH_2120VandenBroucke08.

Akehurst, G., Afonso, C., \& Gonçalves, H. M. (2012). Re-examining green purchase behaviour and the green consumer profile: new evidences. Management Decision, Vol. 50, Issue 5, 972-988. https://doi. org/10.1108/00251741211227726.

Anvar, M., \& Venter, M. (2014). Attitudes and purchase behaviour of green products among Generation Y consumers in South Africa. Mediterranean Journal of Social Sciences, Vol. 5, No. 21, 183-194. https://doi.org/10.5901/ mjss.2014.v5n21p183. 
Bamberg, S., Hunecke, M., \& Blöbaum, A. (2007). Social context, personal norms and the use of public transportation: Two field studies. Journal of Environmental Psychology, Vol. 27, Issue 3, 190-203. https://doi. org/10.1016/j.jenvp.2007.04.001.

Cheah, I., \& Phau, I. (2011). Attitudes towards environmentally friendly products: The influence of ecoliteracy, interpersonal influence and value orientation. Marketing Intelligence \& Planning, Vol. 29, Issue 5, 452-472. https://doi. org/10.1108/02634501111153674.

Ellickson, R. C. (2001). The market for social norms. American Law and Economics Review, Vol. 3, Issue 1, 1-49. https:// doi.org/10.1093/aler/3.1.1.

Follows, S. B., \& Jobber, D. (2000). Environmentally responsible purchase behaviour: a test of a consumer model. European Journal of Marketing, Vol. 34, No.5/6, 723-746. https://doi. org/10.1108/03090560010322009.

Gupta, N., \& Gupta, B. (2015). Peer Influence on Service Purchase Decisions by Young Adults. In Marketing in changing and connecting world (pp. 260-270).

Hair, J.F., Black, W.C., Babin, B.J. and Anderson, R. E. (2010). Multivariate Data Analysis. New Jersey: Pearson.

Hopper, J., \& Nielsen, J. (1991). Recycling as Altruistic Behavior: Normative and Behavioral Strategies to Expand Participation in a Community Recycling Program. Environment and Behavior, Vol. 2, Issue 23, 195-220.

Hustvedt, G., \& Dickson, M. A. (2009). Consumer likelihood of purchasing organic cotton apparel: Influence of attitudes and self-identity. Journal of Fashion Marketing and Management,
Vol. 13, No. 1, 49-65. https://doi. org/10.1108/13612020910939879.

Jansson, J., Marell, A., \& Nordlund, A. (2010). Green consumer behavior: determinants of curtailment and eco-innovation adoption. Journal of Consumer Marketing, Vol. 27, No. 4, 358-370. https://doi. org/10.1108/07363761011052396.

Khare, A. (2015). Antecedents to green buying behaviour: A study on consumers in an emerging economy. Marketing Intelligence and Planning, Vol. 33, Issue 3, 309-329. https://doi. org/10.1108/MIP-05-2014-0083.

Kim, Y., \& Choi, S. M. (2005). Antecedents of Green Purchase Behavior: an Examination of Collectivism, Environmental Concern, and Pce. Advances in Consumer Research, 32, 592-599. Retrieved from http:// www.acrwebsite.org/volumes/9156/ volumes/v32/NA-32http://www. copyright.com/.

Kinzig, A. P., Ehrlich, P. R., Alston, L. J., Arrow, K., Barrett, S., Buchman, T. G., ... Saari, D. (2013). Social Norms and Global Environmental Challenges: The Complex Interaction of Behaviors, Values, and Policy. BioScience, Vol. 63, Issue 3, 164-175. https://doi.org/10.1525/ bio.2013.63.3.5.

Klöckner, C. A., \& Ohms, S. (2009). The importance of personal norms for purchasing organic milk. British Food Journal, Vol. 111, Issue 11, 1173-1187. https://doi. org/10.1108/00070700911001013.

Lee, K. (2009). Gender differences in Hong Kong adolescent consumers' green purchasing behavior. Journal of Consumer Marketing, Vol. 26, Issue 2, 87-96. https://doi. org/10.1108/07363760910940456. 
Makgosa, R., \& Mohube, K. (2007). Peer Influence on Young Adults' Products Purchase Decisions. African Journal of Business Management, Vol. 1, Issue 3, 064-071. https://doi. org/10.22547/ber/8.se.6.

Maxwell, S., \& Garbarino, E. (2010). The identification of social norms of price discrimination on the internet. Journal of Product and Brand Management, Vol. 19, Issue 3, 218-224. https://doi. org/10.1108/10610421011046193.

Michaelidou, N., \& Hassan, L. M. (2008). The role of health consciousness, food safety concern and ethical identity on attitudes and intentions towards organic food. International Journal of Consumer Studies, Vol. 32, Issue 2, 163-170. https://doi.org/10.1111/ j.1470-6431.2007.00619.x.

Moser, A. K. (2015). Thinking green, buying green? Drivers of pro - Environmental purchasing behavior. Journal of Consumer Marketing, Vol. 32, Issue 3, 167-175. https://doi.org/10.1108/ JCM-10-2014-1179.

Newnham, D. (2007). Late adolescent peer group formation in an international hotel school. International Journal of Contemporary Hospitality Management, Vol. 19, No. 2, 159-168. https://doi. org/10.1108/09596110710729265.

Niinimäki, K. (2010). Eco-Clothing, consumer identity and ideology. Sustainable Development, Vol 18, Issue 3), 150-162. https://doi. org/10.1002/sd.455.

Nørgaard, M. K., Hansen, K. N., \& Grunert, K. G. (2013). Peer influence on adolescent snacking. Journal of Social Marketing, Vol. 3, Issue 2, 176-194. https://doi.org/10.1108/ JSOCM-06-2012-0028.
Olsen, S. O., \& Grunert, K. G. (2010). The role of satisfaction, norms and conflict in families' eating behaviour. European Journal of Marketing, Vol. 44, No. 7, 1165-1181. https://doi. org/10.1108/03090561011047571.

Opoku, R. (2012). Young Saudi adults and peer group purchase influence: A preliminary investigation. Young Consumers, Vol. 13, No. 2, 176-187. https://doi. org/10.1108/17473611211233549.

Pratiwi, S. I., \& Pratomo, L. A. (2018). Antecedents of willingness to pay for green products. IOP Conference Series: Earth and Environmental Science, Vol. 106, No. 1. https://doi.org/10.1088/17551315/106/1/012093.

Reynolds, K. J., Subašić, E., \& Tindall, K. (2015). The problem of behaviour change: From social norms to an ingroup focus. Social and Personality Psychology Compass, Vol. 9, Issue 1, 45-56. https://doi.org/10.1111/ spc3.12155.

Ryan, A. M. (2001). The Peer group as a context for the Development of Young Adolescent Motivation and Achievement. Child Development, Vol. 72, Issue 4, 1135-1150.

Setyawan, A., Noermijati, N., Sunaryo, S., \& Aisjah, S. (2018). Green product buying intentions among young consumers: Extending the application of theory of planned behavior. Problems and Perspectives in Management, Vol. 16, Issue 2, 145-154. https://doi.org/10.21511/ ppm.16(2).2018.13.

Sukhu, A., \& Scharff, R. (2010). Will 'doing right' lead to 'doing well'? An examination of green behavior. Journal of Consumer Marketing, Vol. 35, No. 2, 169-182. 
Woodruffe-Burton, H., \& Wakenshaw, S. (2011). Revisiting experiential values of shopping: Consumers' self and identity. Marketing Intelligence and Planning, Vol.
29, No. 1, 69-85. https://doi. org/10.1108/02634501111102760.

Young, H. P. (2007). Social Norms. Discussion Paper Series, (307), 1-16. 